Investigation on Durability and Reactivity of Promising Metal Oxide Sorbents During Sulfidation and Regeneration

Quarterly Report

October - December 1994

K.C. Kwon

January 1995

Work Performed Under Contract No.: DE-FG21-94MC31206

For

U.S. Department of Energy

Office of Fossil Energy

Morgantown Energy Technology Center

Morgantown, West Virginia

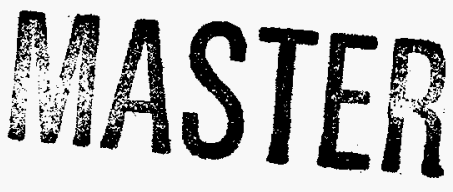

By

Tuskegee University

Tuskegee, Alabama

DISTRIBUTION OF THIS DOCUMENT IS UNLIMTED

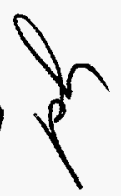




\section{DISCLAIMER}

This report was prepared as an account of work sponsored by an agency of the United States Government. Neither the United States Government nor any agency thereof, nor any of their employees, makes any warranty, express or implied, or assumes any legal liability or responsibility for the accuracy, completeness, or usefulness of any information, apparatus, product, or process disclosed, or represents that its use would not infringe privately owned rights. Reference herein to any specific commercial product, process, or service by trade name, trademark, manufacturer, or otherwise does not necessarily constitute or imply its endorsement, recommendation, or favoring by the United States Government or any agency thereof. The views and opinions of authors expressed herein do not necessarily state or reflect those of the United States Government or any agency thereof.

This report has been reproduced directly from the best available copy.

Available to DOE and DOE contractors from the Office of Scientific and Technical Information, 175 Oak Ridge Turnpike, Oak Ridge, TN 37831; prices available at (615) 576-8401.

Available to the public from the National Technical Information Service, U.S. Department of Commerce, 5285 Port Royal Road, Springfield, VA 22161; phone orders accepted at (703) 487-4650. 
品

눙

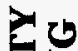

23

부음응

的象

要

올

द姑

웅응

5 됟

붕

$\$ 24$

음릉

중룰

눙

夏官

䝿的

능

得

3

ริ

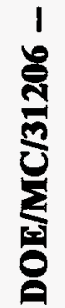




\title{
Investigation on Durability and Reactivity of Promising Metal Oxide Sorbents During Sulfidation and Regeneration
}

\author{
Quarterly Report \\ October - December 1994 \\ K.C. Kwon
}

Work Performed Under Contract No.: DE-FG21-94MC31206

\author{
For \\ U.S. Department of Energy \\ Office of Fossil Energy \\ Morgantown Energy Technology Center \\ P.O. Box 880 \\ Morgantown, West Virginia 26507-0880 \\ By \\ Tuskegee University \\ Chemical Engineering Department \\ School of Engineering \& Architecture \\ Tuskegee, Alabama 36088
}




\begin{abstract}
Hot-gas desulfurization for the integrated gasification combined cycle (IGCC) process has been investigated by many researchers to remove effectively hydrogen sulfide with various metal oxide sorbents at high pressures and high temperatures. Metal oxides such as zinc titanate oxides, zinc ferrite oxide, copper oxide, manganese oxide and calcium oxide, were found to be promising sorbents in comparison with other removal methods such as membrane separations and reactive membrane separations. Some metal oxide sorbents exhibited the quite favorable performance in terms of attrition resistance and sulfur capacity. Removal reaction of $\mathrm{H}_{2} \mathrm{~S}$ from coal gas mixtures with ZT-4 or other promising sorbents of fine solid particles, and regeneration reaction of sulfur-loaded sorbents will be carried on in a batch reactor or a continuous differential reactor.

The objectives of this research project are to find intrinsic initial reaction kinetics for the metal oxide-hydrogen sulfide heterogeneous reaction system, to obtain effects of concentrations of coal gas components such as hydrogen, carbon monoxide, carbon dioxide, oxygen, nitrogen and moisture on equilibrium reaction rate constants of the reaction system at various reaction temperatures and pressures, to identify regeneration kinetics of sulfurloaded metal oxide sorbents, and to formulate promising metal oxide sorbent for the removal of sulfur from coal gas mixtures. Promising durable metal oxide sorbents of high-sulfurabsorbing capacity will be formulated by mixing active metal oxide powders with inert metal oxide powders and calcining these powder mixtures, or impregnating active metal oxide sorbents on supporting metal oxide matrixes.
\end{abstract}

The Research Triangle Institute, a sub-contractor of this research project, will also prepare promising metal oxide sorbents for this research project, plan experiments on removal of sulfur compounds from coal gases with metal oxide sorbents as well as regeneration of sulfur-loaded metal oxide sorbents, and review experimental results. 
CONTENTS

Page

ABSTRACT ..............................

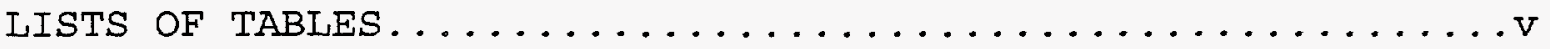

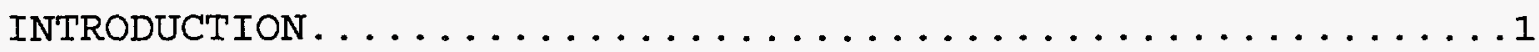

STATEMENTS OF RESEARCH OBJECTIVES...............

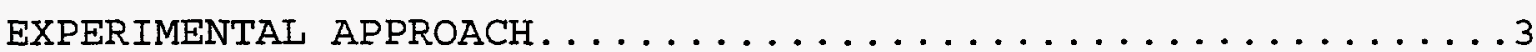

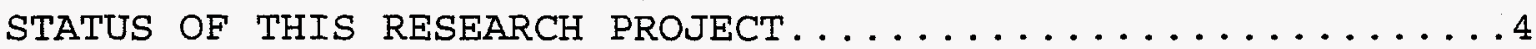

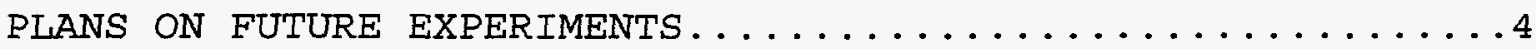




\section{LISTS OF TABLES}

Table

1 Major equipment have been placed on order. .........5

2 Chemicals have been placed on order. $\ldots \ldots \ldots \ldots \ldots$

3 Parts and supplies have been placed on order. .......6

4 Formulation of Metal Oxide Sorbents. .............

5 Chemical properties of the ZT-4 sorbent, formulated ...7 with 5-w\% bentonite at the nominal $\mathrm{Zn}$ to $\mathrm{Ti}$ ratio

of 1.5 , and the nominal particle size of 100 to $400 \mu \mathrm{m}$, calcined at $825^{\circ} \mathrm{C}$ for 2 hours.

6 Reaction conditions on both conversion of carbon ......7 disulfide into hydrogen sulfide and sulfidation of metal oxide sorbents.

7 Reaction conditions on both decomposition of $\ldots \ldots \ldots \ldots 7$ hydrogen peroxide and regeneration of sulfided metal oxide sorbents. 


\section{INTRODUCTION}

Coal is the most plentiful energy resource in the United States and continues to be the major fuel utilized by electrical power plants. The coal resources will become more attractive for chemical feedstocks as well as sources of liquid and gaseous fuels, as petroleum resources become more depleted.

Coal is a very complex and heterogeneous material. Effective utilization of coal requires an understanding of the formation, structure, and purification of coal. Raw coal consists of minerals and organic matter. Coal minerals include primarily pyrites, silicate (quartz, clays) and various minor minerals, whereas organic matter is composed of carbon, oxygen, hydrogen, nitrogen and sulfur. Sulfur in coal is present as organic sulfur, pyritic sulfur and sulfate sulfur. Sulfur occurring in the form of relative coarse pyrite particles is removed largely by density separation, but very finely disseminated pyrite and organic sulfur cannot be removed in this way. Sulfur products in combustion not only pollute the environment, but also are detrimental to combustion systems because of the corrosive action of their combustion products. In gasification process, coal is reacted with steam and air or oxygen to produce a medium to high calorific value fuel gas. The fuel gas can be subsequently combusted in a gas/steam turbine combined cycle (IGCC). These IGCC-based power generation options offer much higher thermodynamic cycle efficiencies that promise to reduce all forms of pollutants released from a coal conversion process through a lower fuel consumption and from the use of more energy efficient high pressure and/or temperature unit operations for the removal of environmental pollutants. Among these options, integrated gasification combined cycles (IGCC) are relatively well developed.

Sulfur products in combustion of sulfur present in coal not only pollute the environment, but also are detrimental to combustion systems because of the corrosive action of their combustion products. Removal of hydrogen sulfide from hot coal gas produced in integrated gasification combined cycle power generation systems by metal oxide sorbents is required to protect downstream combustion turbines from being corroded with sulfur compounds.

Removal of sulfur compound from coal gas products are investigated by using various metal oxide sorbents, and membrane separation methods. Current research results show that removal of sulfur with metal oxide sorbents appear to be the most promising method among others.

Main requirements of these metal oxide sorbents are durability and high sulfur-loading capacity during absorption-regeneration cycles. Spalling of sulfur-loaded fixed-bed metal oxide sorbents occurs during the regeneration of sulfur-loaded metal sorbents. The main causes of spalling of sorbents appear to be temperature rises of sulfur-loaded sorbents due to tremendous exothermic heat of reaction, and sulfate formation during regeneration processes. Sulfate products occupy more space than sulfide products in pores of sorbents, and result in significant structural stresses of metal sorbents.

The main objectives of this research proposal are to formulate durable metal oxide 
sorbents of high-sulfur-absorbing capacity by the physical mixing method or the impregnation method, to investigate reaction kinetics on the removal of sulfur compounds from coal gases at high temperatures and high pressures, and to study kinetics on regeneration of sulfided sorbents, using formulated promising metal oxide solid sorbents.

\section{STATEMENTS OF RESEARCH OBJECTIVES}

Experiments will be conducted in an isothermal stirred micro batch reactor or an isothermal continuous differential reactor to obtain kinetic data on both sulfidation of metal oxide sorbents and regeneration of sulfided metal oxide sorbents, and experimental data on mechanical/thermal stabilities of formulated metal oxide sorbents suitable for the design of bench-scale/pilot-scale transport reactors.

(a) Metal-oxide sorbents with high reactivity/capacity and thermal/mechanical stability/durability will be formulated by the physical mixing method or the impregnation method.

(b) Experimental procedures will be developed for both sulfidation and regeneration reactions of formulated metal oxide sorbents at high pressures and high temperatures.

(c) Analytical procedures will be developed for the analysis of concentrations of both sulfur dioxide and hydrogen sulfide in a reaction product gas mixture.

(d) Thermal/mechanical stability of formulated metal oxide sorbents from cyclic sulfidation/regeneration reactions will be investigated in the isothermal stirred batch reactor or the isothermal continuous differential reactor.

Effects of reaction variables on sulfidation/regeneration reaction kinetics will be investigated for formulated promising metal oxide sorbents. The reaction variables include concentrations of coal gas components, total pressures, reaction temperatures, space velocities of gases for continuous differential reactor operations, initial mass ratios of coal gases to sorbents for batch reactor operation operations, particle sizes of sorbents, and pore volumes of sorbents.

(a) Effects of concentrations of coal gas components such as hydrogen, nitrogen, oxygen, carbon monoxide, carbon dioxide, and moisture on both sulfidation and regeneration reaction kinetics will be evaluated at various reaction temperatures and pressures, using a stirred batch reactor.

(b) Effects of total pressures and reaction temperatures on sulfidation/regeneration reaction kinetics for formulated metal oxide sorbents will be determined in a stirred batch reactor or a continuous differential reactor. 
(c) Roles of initial mass ratios of sorbents to sulfidation/regeneration gas mixtures, particle sizes of sorbents, and pore volumes of sorbents will be found, using a stirred batch reaction system.

(d) Roles of space velocities of regeneration gas mixtures, and particle sizes of sorbents, pore volumes of sorbents will be delineated, using a continuous differential reaction system.

\section{EXPERIMENTAL APPROACH}

The main objectives of this project are to investigate reaction kinetics on the removal of sulfur compounds from coal gases at high temperatures and high pressures, using promising solid metal oxide sorbents, to study kinetics on the regeneration of sulfided sorbents, and to formulate promising durable metal oxide sorbents of high-sulfur-absorbing capacity.

During the first year, fresh metal oxide sorbent particles with promising formulas and simulated coal gases containing hydrogen sulfide are introduced in a batch reactor. The batch reactor, loaded with the fresh sorbent and the simulated coal gas mixture, is submerged in a fluidized sand bath to maintain the heterogeneous reaction system at a desired reaction temperature. Fine metal oxide sorbents will be used to minimize effects of intraparticle diffusion of hydrogen sulfide through sulfided sorbent particles. The batch reactor, loaded with a mixture of fresh sorbent and simulated coal gas mixtures, is shaken in a constanttemperature fluidized sand bath to reduce effects of mass transfer of hydrogen sulfide to sorbent particles. The sulfidation reaction is terminated at the desired reaction time. Conversions of sorbents are analyzed with an electronic balance and a gas chromatograph.

Experiments on the regeneration of sulfided sorbents will be conducted in the batch reactor. Effects of regeneration temperatures, regeneration pressures, and concentrations of regeneration gases such as oxygen, nitrogen, and moisture on regeneration rate will be investigated in the batch reactor.

Precise laboratory procedures will be developed for $\mathrm{H}_{2} \mathrm{~S}$-sorbent heterogeneous reactions in a batch reactor at high pressures and high temperatures. This will involve developing procedures for the proper set-up of a batch reactor and a gas chromatograph for the reaction system. Experiments on intrinsic initial reaction kinetics as well as regeneration kinetics will be performed for the metal-oxide sorbents- $\mathrm{H}_{2} \mathrm{~S}$ heterogeneous reaction system. Known amounts of carbon disulfide aqueous solution of various concentrations as a hydrogen sulfide feed stock will be introduced in the batch reactor. Carbon disulfide is decomposed in the presence of hydrogen to produce hydrogen sulfide at precise desired quantities. Known amounts of hydrogen peroxide aqueous solution of various concentrations, as an oxygen feedstock, will be fed into the batch reactor. 


\section{STATUS OF THIS RESEARCH PROJECT}

Research activities and efforts of this research project were concentrated on selecting and ordering various equipment, chemicals and supplies suitable for this research project during the period of October-December 1994. Several pieces of experimental equipment have been ordered, as shown in Table 1. Most equipment have not been delivered.

All the ordered chemicals for this research project have been delivered, as shown in Table 2. Initial experiments on formulating metal oxide sorbents were performed, using flour powder as an organic burnout, zinc oxide powder as an active sorbent ingredient, bentonite as a binding material and titanium oxide as a supporting metal oxide, as shown in Table 4 . This pasty mixture was extrudated $1 / 16$-inch cylindrical rods. The viscosity of the pasty mixture appeared to be sensitive to amounts of distilled water as well as amounts of flour powder added to the powder mixture. Homogeneous mixing of these pasty slurry mixtures appeared to be very important in producing duplicate formulations of sorbents

\section{PLANS ON FUTURE EXPERIMENTS}

Reactivities of carbon disulfide with hydrogen will be investigated in a micro batch reactor. Carbon disulfide and hydrogen will be utilized as a source of hydrogen sulfide for the sulfidation reaction of sulfur-free sorbents. Reactivities of carbon disulfide with steam also will be investigated for the possible source of hydrogen sulfide for this research. Hydrogen peroxide will be used as a source of oxygen for the regeneration of sulfur-loaded sorbents. Decomposition of hydrogen peroxide in the presence of steam and nitrogen will be investigated in a batch reactor. Initial reaction kinetics on both sulfidation of sulfur-free sorbents and regeneration of sulfided sorbents will be conducted with the ZT-4 sorbent from the Research Triangle Institute, as shown in Table 5. Reaction conditions on sulfidation of metal oxide sorbents are shown in Table 6, whereas reaction conditions on regeneration of sulfided metal oxide sorbents are shown in Table 7. 
Table 1. The following major equipment have been placed on order, and some of them have been delivered.

Item Equipment/Description Supplier Remarks

No.

1 Gas Chromatograph with Temperature

Programmable Oven, a single

On-Column Injector, and a

digital gas flow controller, serial data port

2 FPD Detector

3 Thermal Conductivity Detector

4 Additional Injector

5 Stainless Steel Pressure Transducer

0 - 1000 psig, 1/8-NPT Pressure

Port. 187 Push-On Terminal Flat

Connections.

6 Universal Meter

BUCK Scientific undelivered

High Performance Process Indicator with Built-IN Transducer Excitation, Millivolt/Voltage Inputs for Strain Gage Meters, Voltage/Current Inputs, Thermocouple Inputs. Scalable

Analog Output Isolated RS-232

Communications

$7 \quad 25-$ Pin Serial Connector for RS232

8 Tempcore Top Bench, 72"x36" Non-Warping

9 51/2" Heavy-Duty Vise, Open to 6 inch. Sears Tools

OMEGA ENGINEERING delivered

Global National undelivered

Scientific

BUCK Scientific

BUCK Scientific

OMEGA ENGINEERING

OMEGA ENGINEERING delivered

undelivered

undelivered

delivered

undel ivered

Sears Tools

undelivered

undelivered

undel ivered

Sears Tools

undelivered

12 15-inch Adjustable Wrench, 2.88 lbs $1800 \mathrm{~W}, 51$ lbs, Chamber WXHXD:

$9 " \times 7 " \times 9 ", 100-120 \mathrm{~V}$. New three-stage

Programmable. Actual or Set

Temperatures shown in LED. Program and Display in either ${ }^{\circ} \mathrm{C}$ or ${ }^{\circ} \mathrm{F}$, Ney model number 3-550, Ney part number 9493308. 
Table 2. The following chemicals have been placed on order, and secured for this research project.

$\begin{array}{llrll}\text { Item } & \text { Chemicals } & \begin{array}{c}\text { Quantity, } \\ \text { No. }\end{array} & \text { Supplier } & \text { Remarks } \\ 1 & \text { FERRIC ACETATE } & 100 & \text { Pfaltz \& Bauer } & \text { delivered } \\ 2 & \text { MANGANESE ACETATE } & 500 & \text { Pfaltz \& Bauer delivered } \\ 3 & \text { FERRIC NITRATE } & 500 & \text { Pfaltz \& Bauer delivered } \\ 4 & \text { TITANIUM DIOXIDE } & 2000 & \text { Pfaltz \& Bauer } & \text { delivered } \\ 5 & \text { ZINC OXIDE } & 1000 & \text { Pfaltz \& Bauer } & \text { delivered } \\ 6 & \text { AMMONIUM MOLYBDATE } & 500 & \text { Alfa Aesar } & \text { delivered } \\ 7 & \text { COBALT ACETATE } & 250 & \text { Alfa Aesar } & \text { delivered } \\ 8 & \text { CUPRIC ACETAtE } & 500 & \text { Alfa Aesar } & \text { delivered } \\ 9 & \text { ZINC ACETATE } & 1000 & \text { Alfa Aesar } & \text { delivered } \\ 10 & \text { NICKEL ACETATE } & 250 & \text { Alfa Aesar } & \text { delivered } \\ 11 & \text { TITANIUM ISOPROPOXIDE } & 500 & \text { Alfa Aesar } & \text { delivered } \\ 12 & \text { TITANIUM TETRACHLORIDE } 1000 & \text { Alfa Aesar } & \text { delivered } \\ 13 & \text { Bentonite } & 500 & \text { Integra } & \text { delivered } \\ 14 & \text { Hydrogen Peroxide, 30 w\% } 500 & \text { Integra } & \text { delivered } \\ 15 & \text { Carbon Disulfide } & 500 & \text { Integra } & \text { delivered }\end{array}$

Table 3. The following parts and supplies have been placed on order.

Item Parts \& Supplies/Description Supplier Remarks

No.

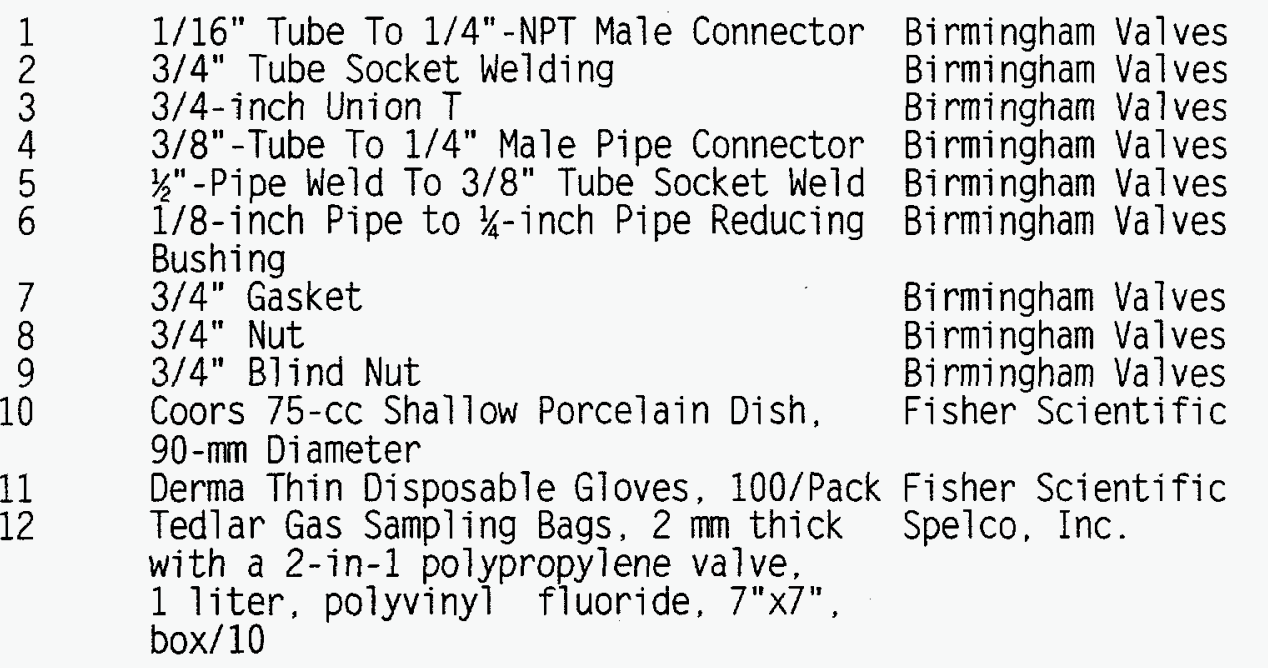

delivered delivered delivered delivered delivered delivered

delivered delivered delivered delivered

delivered undelivered

Table 4. Formulation of Metal Oxide Sorbents.

\begin{tabular}{cccccc} 
Run \# & \multicolumn{5}{c}{ Components/Ouantity, $\mathrm{g}$} \\
\cline { 3 - 6 } & & \multicolumn{5}{c}{ Ti0 } & Bentonite & Flour & Water \\
1 & 1.0 & 2.0 & 0.1 & 0.3 & 2.0 \\
2 & 1.0 & 2.0 & 0.3 & 0.6 & 3.5
\end{tabular}

Remarks 
